\title{
Skin cancer knowledge and attitudes in the region of Fez, Morocco: a cross-sectional study
}

\author{
Awatef kelati ${ }^{*}$, Hanane Baybay ${ }^{1}$, Mariam Atassi ${ }^{2}$, Samira Elfakir ${ }^{2}$, Salim Gallouj ${ }^{1}$, Mariame Meziane ${ }^{1}$ \\ and Fatima Zahra Mernissi ${ }^{1}$
}

\begin{abstract}
Background: The prevalence of skin cancers is constantly increasing in Morocco, and they have gradually become more aggressive due to a significant delay in the diagnosis. Our aim was to assess the levels of awareness and the influencing factors related to skin cancer knowledge in Morocco.

Methods: This cross-sectional study was carried out in Morocco through the medium of a validated questionnaire, which contained several items - demographics, skin cancer knowledge and attitudes towards skin cancer patients- during a period of 1 year (2014).

Results: Out of the 700 participants enrolled in the study, 17.9\% had never heard of skin cancer, 32.5\% had a low score of skin cancer knowledge, $66.7 \%$ had a moderate score, and only $0.85 \%$ had a high score of skin cancer knowledge. Further, $15.1 \%$ of the participants were under the assumption that this cancer is contagious. The sun was the most incriminated risk factor in skin cancer occurrence by $74.3 \%$ of the participants, and $57.9 \%$ of them believed that prevention is important through using various means of photoprotection. After univariate and multivariate analysis, the influencing factors related to the skin cancer knowledge in Morocco were: the socioeconomic status $(P=0.003, \mathrm{OR}=7.3)$ and the educational level $(p<0.001, \mathrm{OR}=20.9)$.
\end{abstract}

Conclusions: Due to the lack of knowledge or the underestimation of skin cancer in our study population, efforts are needed to promote skin cancer surveillance behaviors in Morocco.

Keywords: Cross-Sectional study, Skin cancer, Epidemiology, Knowledge, Attitudes, Morocco

\section{Background}

Skin cancer (SC) is the most common worldwide malignancy and it a preeminent global public health problem [1]. These SCs are divided into two main groups in Morocco: melanoma and non-melanoma SCs (NMSC), these last tumors are mainly basal cell carcinoma (BCC) and squamous cell carcinoma (SCC), and also cutaneous lymphomas, Sarcomas in addition to rare types such as adnexal tumors and Merkel cell carcinoma [2].

In Morocco, because of the absence of a national cancer registry, the exact number of incidence and

\footnotetext{
* Correspondence: awatkelati@gmail.com

'Department of dermatology, University Hospital Hassan II, 202 Hay

Mohamadi, Fez, Morocco

Full list of author information is available at the end of the article
}

mortality of SC is not available. However, according to regional records -Casablanca register of cancers (2004), Cancer registry of the National Institute of Oncology Sidi Mohamed Ben Abdellah, Rabat (2002-2007) and Rabat register of cancers (2009)- and a few publications, a change in the distribution of different SCs was noted; the prevalence of melanoma and lymphoma increased from $3,5 \%$ and $1,5 \%$ to $10,4 \%$ and $18,6 \%$ of skin malignancies in a period of 19 years; while the prevalence of the SCC and BCC decreased from 58\% and $32 \%$ to $26,9 \%$ and $23,7 \%$ in the same period [2]; with a decrease in the proportion of skin carcinomas at the expense of Melanoma: $50.6 \%$ of carcinomas during the period 1992-2011 against 90\% during the period 1971-1991. 
There were also an increase in melanomas' aggressivity, in a study of 30 melanomas made in the region of Fez-Boulmane [3], Breslow index was more than $4 \mathrm{~mm}$ in 33\%, 56 patients had metastasis and 2 patients died; while these numbers have almost doubled in a recent cohort of 70 cases of melanoma, carried out in the same region (unpublished data of the Moroccan Society of Dermatology), the Breslow at the moment of the diagnosis was $>4 \mathrm{~mm}$ in $50 \%$ of cases, with 4 cases of death.

Because of this increase, the costs attributable to the diagnostic delay and noneffective health care procedures are now an economic burden and they are a problem for health care services worldwide, for example, Medical costs to treat SCs in the USA are estimated at $\$ 3$ billion annually [4].

However, the most important fact about SC is that it is mostly preventable with the health care promotion and the early detection endeavors. [5] When discovered early, the survival rate for individuals with melanoma is $>98 \%$, as compared with $15 \%$ of those diagnosed with advanced disease. That's why health care providers should be promoting the establishment of appropriate strategies to ultimately improve the preventive provision of care for these cancers, by carrying out programs to evaluate the degree of awareness of populations with this problem and the benefit of the prevention of these risk factors especially sun exposure. Kyle and al. [5] reported that every dollar spent on sun safety educational initiatives saves the nation almost $\$ 4$ in health care costs, in addition to a reduction in morbidity and mortality associated with SC.

In emerging Countries like Morocco, SC is not a public health priority, and it is usually underestimated. For this reason, before thinking about effective preventive measures, studies must be carried out to investigate $\mathrm{SC}$ knowledge in our populations.

The aim of the present study was to assess the level of awareness, and the influencing factors related to SC knowledge in Morocco, and to detect attitudes towards SC patients based on the degree of awareness of our population.

\section{Methods}

\section{Study design}

This was a cross-sectional study, spread over a period of 1 year between March 2014-March 2015 in the city of Fez in Morocco.

\section{Participants}

Participants aged more than 18 years old were randomly selected from different categories of the Moroccan population with different educational levels (ELs) and socioeconomic levels using a systematic sampling method: from the daily list of patients of other specialities' consultations and their accompanists in the Hospital Hassan II of Fez, Morocco.

\section{Data collection}

The data collection was based on filling a five-minute questionnaire by participants, in a "face to face" way with the investigator, in order to help them especially those with a low EL who can't read the questionnaire by themselves. Investigators were volunteers from the medical staff of the departments of dermatology and clinical epidemiology of the Hospital Hassan II of Fez.

The questionnaire consisted of 42 questions with several items: demographics, SC knowledge, attitudes towards SC patients, use of photoprotection measures, and the relationship with the doctor. The questions about SC knowledge were included in Table 1.

This questionnaire was validated in a multidisciplinary meeting, including experts in Dermatology, Clinical epidemiology, Scientific research and a psychiatrist.

Epidemiological and sociodemographic data of participants included: age, gender, highest level of education, health insurance status, profession and salary, medical records of participants and their phototype (filled by the investigator); then, participants were asked if they heard about SC and from who (health professional, relatives or media) and if they know someone who suffers from this disease and how he lived the experience; then, they completed questions regarding their knowledge about SC (risk factors especially sun exposure, clinical manifestations, location, contagiosity and treatment), in addition to SC eventually preventive measures (sunscreen use, shade seeking, and use of sun protective clothing).

Also, the questionnaire explored the participant's opinion of how must be the relationship between the physician and the patient, and how to announce the diagnosis (direct way or progressive way), and if the psychiatric care is obligatory for patients instead of, or accompanied by the family support.

Participants used a 3-point response scale (yes, no, I don't know or others) to indicate their response to the questions.

A score of SC knowledge level was established based on correct answers from 0 to 27: a low level of knowledge

Table 1 The questions about SC knowledge

Questions of SC knowledge

1) Have you ever/never heard of skin cancer?

2) Is it dangerous?

3) Could It kill

4) Clinical manifestations (multiples choices) (Table 3)

5) Alarming symptoms (multiples choices) (Table 3 )

6) Skin cancer risk factors (multiples choices) (Table 3)

7) Its relationship with the phototype

8) Do you think that it appears in a pre-existing lesion?

9) Is mucosal involvement possible?

10) Do you know someone who has this skin cancer?

11) The reaction of the participant towards skin cancer patient

12) Relationship with the doctor: how should the doctor announce the diagnosis? 
was described if the participant had less than 10 correct answers, a moderate level of knowledge if the participant had between 10 and 20 correct answers, and a high level of knowledge if the participant had more than 20 correct answers.

Socioeconomic level (SEL) was considered low if the monthly salary was less than 3000 DH (294.30 USD), moderate if it was between 2000DH (196.20 USD) and $7000 \mathrm{DH}$ (686.70 USD), and high if it was more than 7000 DH (686,70 USD).

\section{Statistical analysis}

A descriptive, univariate and multivariate analysis using the SPSS 20 software were performed.

In the descriptive analysis, quantitative variables were expressed by means \pm standard deviation and qualitative variables by percentages. In the univariate analysis, the "Chi-square" test was used to compare percentages in order to determine the factors associated with the knowledge level. In the multivariate analysis, high and moderate levels of knowledge were grouped into one group of an appropriate level of SC knowledge, and a logistic binary regression was performed including variables for which the $\mathrm{p}$ value in the univariate analysis was less than 0.20 , then a step down method was carried out. A p value less than 0.05 was considered statistically significant.

\section{Results}

We had included 700 subjects in this survey, the average age of participants was 33.6 years $(\mathrm{SD}=13.3$ years). There was a female predominance $(61.9 \%)$ and $64.1 \%$ of participants were in a moderate SEL (Table 2).

$17.9 \%$ of the participants had never heard of SC, and $15.1 \%$ of them thought that it was contagious.

$32,5 \%$ of the participants had a low score of SC knowledge level, $66.7 \%$ had a moderate score and only $0.85 \%$ had a high score of SC knowledge level (Table 3).

The sun was the factor the most incriminated in the pathogenesis of SC (74.3\%) and $57.9 \%$ of the participants believed that it is important to use various means of photoprotection as sunscreens (34.2\%), clothes $(11 \%)$ or avoiding the exposition to the sun between 10 am and $16 \mathrm{pm}(29 \%)$.

Regarding the relationship between the doctor and the patient, $58.4 \%$ of the participants thought that the doctor has to announce the diagnosis of cancer to the patient gradually, while $23.3 \%$ of the participants preferred the direct way, and $18.3 \%$ of them thought that the diagnosis must be hidden to the patient (Table 4).

In the univariate analysis, younger participants ( $<45$ years) and subjects with a moderate or a high SEL $(p<10-4)$ and a high EL $(p<0.001)$ had an appropriate level of SC
Table 2 Descriptive analysis of epidemiological characteristics of participants

\begin{tabular}{lll}
\hline Epidemiological characteristics & $N=700$ & $\%$ \\
\hline Age groups & 5 & 0.7 \\
$\quad<15$ years old & 548 & 78.3 \\
15-45 years old & 147 & 21.1 \\
$>45$ years old & & \\
Gender & 438 & 62.5 \\
F & 262 & 37.4 \\
M & & \\
Phototype & 93 & 13.2 \\
III & 489 & 69.8 \\
IV & 118 & 16.8 \\
V & & \\
Educational level & 357 & 51 \\
Academic (university) & 164 & 23.4 \\
High school & 68 & 9.7 \\
Primary education & 111 & 15.9 \\
Illiterate & & 23.8 \\
Socioeconomic level (SEL) & 167 & 9.7 \\
Low SEL & 68 & \\
High SEL & 449 & \\
Moderate SEL & & \\
\hline
\end{tabular}

knowledge, and they emphasized the importance of the photoprotection and the psychiatric care for these patients.

Sources of information about $\mathrm{SC}$ varied according to the age $(P=0.03)$ and the EL $(P=0.02)$. Each category of the population had a different source of information; young persons with a moderate and a high EL used the internet, while television was the source of information of illiterates and aged persons.

Behaviors of the participants were influenced by their EL; the more the EL was increased, the more the participants preferred to stay away from SC patients or they remain indifferent to them because it could be contagious, and it was analphabets and the persons with a low EL who thought that they must support these patients even though it could be contagious $(p<0.001)$.

Men preferred the direct relationship between the doctor and the patient, especially the way to announce the diagnosis of cancer (38\%), while women thought that the doctor must announce it gradually $(60.5 \%)$ or not to announce it at all $(20.3 \%)(p=0.02)$ (Table 4).

After the multivariate analysis, the influencing factors related to SC knowledge in our Moroccan population were the SEL $(P=0.003, \mathrm{OR}=7.306$, IC $95 \%=(1.9-27.5))$, and the EL $(p<0.001$, OR $=20.9$, IC $95 \%=(10.5-41.6))($ Table 5). 
Table 3 Descriptive analysis of the questionnaire items about skin cancer knowledge

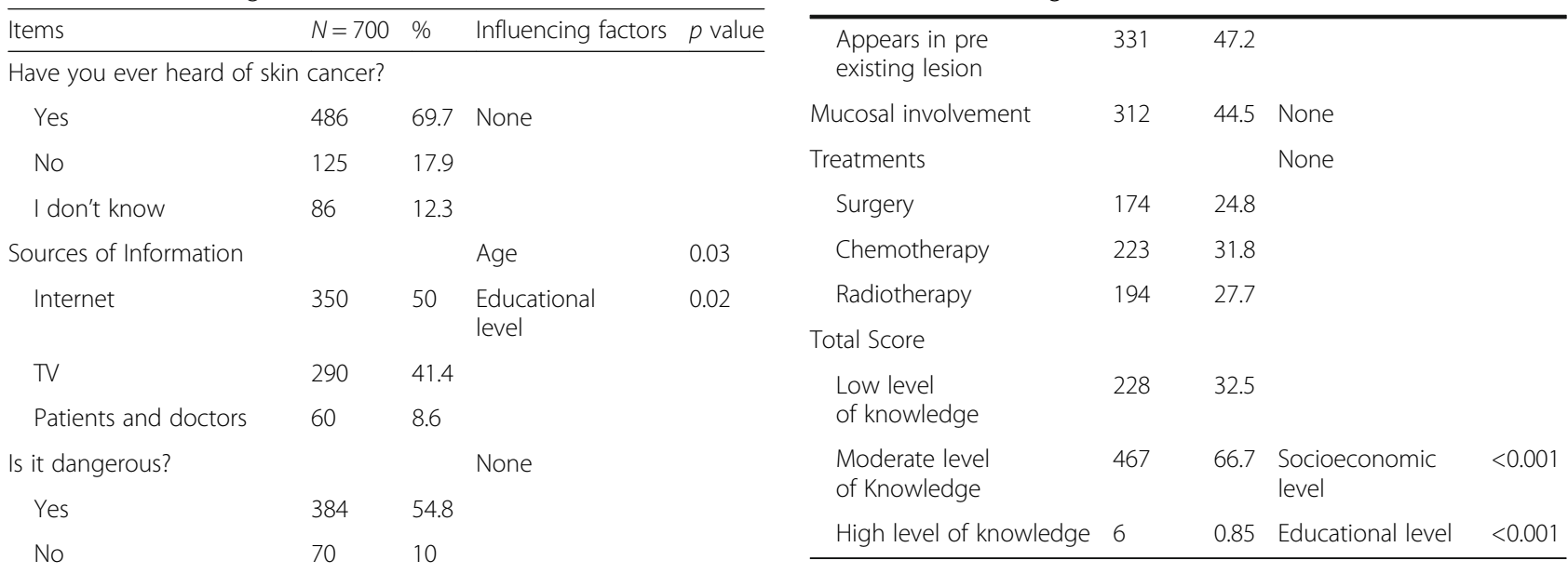

I don't know $\quad 246 \quad 35.1$

It could kill

Yes

No

I don't know

Clinical manifestations

Papules

Nodules

Tumors

Ulcers

Purulent bubbles

Black patches

Others

Alarming symptoms

Size increase
Color change
Resistance to
usual treatment
Pruritus

Skin cancer risk factors

Sun Exposure

Genetic factors (Family history of skin cancer)

Chemical products

Irradiation

Infection

Smoking

Relationship with the phototype (324/46.3\%)

Fair skin

Dark skin

Appears without pre existing lesion

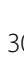

304

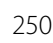

44.3 None

35.7

14620

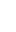

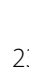

234

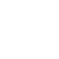

126

174

213

121

20

384

2.9

5.6

None

$344 \quad 74.3$

$235 \quad 51$.

$230 \quad 49.8$

$207 \quad 44.7$

$171 \quad 37$

$121 \quad 26.5$

None

$300 \quad 42.8$

$70 \quad 10$

$142 \quad 20.2$ None

Discussion

SC is the most common malignancy [6-14]; and it increases dramatically, especially Melanoma [2], which has a faster growing incidence and a higher mortality rate than that of any other malignancy [15]. The underlying reasons for this increase were discussed in many studies that have confirmed the development of risk factors such as sun exposure; chronic and repeated in both BCC and SCC, while intense sun exposure and a history of sunburn was linked to melanoma [3]. Furthermore, a history of multiple moles ( $>50)$, atypical moles, light skin, red or blond hair, blue or green eyes, freckles, history of sunburn, or family history of melanoma are considered higher risks for developing melanoma [4], other risk factors especially for NMSC are an immunosuppression, human papilloma virus, chronic wounds and burns...

Compared with other cancer types, SC treatment costs are currently low because it can be primarily treated efficiently in an office-based setting. NMSC care cost stands in fifth place after prostate, lung, colon, and breast carcinomas. But, due to its considerable frequency, its final cost would be huge and depends on 2 factors: care settings and treatment modalities [2-16].

This present study is -to our knowledge- the first Moroccan, North African and among the first occidental studies interested in assessing the knowledge level, attitudes, and behaviors related to SC. Apart from three similar studies conducted on youths in Maryland [17] and in the USA [18], and the survey of Gordon R and al. that concluded to an overall low levels of knowledge about SCs especially melanoma $[19,20]$. Other few studies interested only in the relationship between the sun, the photoprotection and SCs were performed [21-26], or conducted on minorities and targeted populations like golfers [6]. Similarly to these studies, the sun was the factor the most incriminated in the etiopathogenesis of skin cancer in our study (74.3\%), and $57.9 \%$ of the 
Table 4 Descriptive analysis of participants' responses about behaviors towards skin cancer patients and the relationship with the doctor

\begin{tabular}{|c|c|c|c|c|c|}
\hline Items & $N(\%)=700$ & $\begin{array}{l}\text { Men N(\%) } \\
262(37.4 \%)\end{array}$ & $\begin{array}{l}\text { Women } N(\%) \\
438(62.5 \%)\end{array}$ & Influencing factors & $p$ value \\
\hline \multicolumn{6}{|l|}{ Relationship with skin cancer patients } \\
\hline \multicolumn{4}{|l|}{ Do you know someone who has this skin cancer? } & \multirow[t]{3}{*}{ None } & \\
\hline Yes & 139 (19.9) & $55(21)$ & $84(19.2)$ & & \\
\hline No & $561(80.1)$ & 207(79) & $354(80.1)$ & & \\
\hline \multicolumn{4}{|l|}{ The reaction of the participant towards skin cancer patient } & \multirow[t]{4}{*}{ Educational level } & \multirow[t]{4}{*}{$<0.001$} \\
\hline Remoteness (contagious) & $90(15.1)$ & $34(13)$ & $56(12.7)$ & & \\
\hline Indifferent & $181(30.4)$ & $75(28.6)$ & $106(24.2)$ & & \\
\hline Support & $324(54.5)$ & $153(58.4)$ & $276(63)$ & & \\
\hline \multicolumn{4}{|l|}{ The psychiatric care is obligatory for skin cancer patients } & \multirow[t]{4}{*}{ None } & \\
\hline Yes & $358(51.1)$ & $122(46.5)$ & $233(53.1)$ & & \\
\hline No & $202(29)$ & $33(12.6)$ & $40(9.1)$ & & \\
\hline I don't know & $140(20)$ & $107(40.8)$ & $165(37.6)$ & & \\
\hline \multicolumn{4}{|c|}{ Relationship with the doctor: how should the doctor announce the diagnosis? } & \multirow[t]{4}{*}{ Gender } & \multirow[t]{4}{*}{0.02} \\
\hline Direct way & $157(23.3)$ & $99(38)$ & $84(19.1)$ & & \\
\hline Progressive way & $393(58.4)$ & $147(56.1)$ & $265(60.5)$ & & \\
\hline Hiding the diagnosis to the patient and inform just his family & $123(18.4)$ & $16(6.1 \%)$ & $89(20.3)$ & & \\
\hline
\end{tabular}

participants believed that it is important for the SC prevention using various measures especially sunscreens.

We have found that $17.9 \%$ of participants, especially those with a low EL had never heard of SC, which is a real issue because this category not only underestimated this cancer and may have a poor sense of risk-reducing strategies for SC, but they would never come to see the doctor in the early stage of the disease, which explain why we still see historical tumors with bad prognosis and metastasis. Also, another possible factor of delay in our context is the frequent use of traditional medicine such as fire and plants.

Another common error in our population is the idea that SC is contagious, which was the participants' opinion in $15.1 \%$ of cases; and that it is due to germs (37\%). This idea of contagious disease would not only influence the patient, but also his integrity in the society, which

Table 5 Multivariate analysis showing the association between factors and SC knowledge score

\begin{tabular}{lcccc}
\hline Variables & $P$ value & OR & Cl 95\% & \\
\hline SEL & & & & \\
Low SEL & 0.000 & 4.232 & 2.550 & 7.023 \\
Moderate and high SEL & 0.003 & 7.306 & 1.936 & 27.567 \\
Educationnal level & & & & \\
Academic (university) & 0.000 & 20.996 & 10.584 & 41.651 \\
High school & 0.000 & 3.332 & 1.834 & 6.052 \\
Illiterates and primary education & 0.038 & 2.136 & 1.041 & 4.382 \\
\hline
\end{tabular}

will surely make the situation more complicated with a real impact on the patient's life quality.

What was surprising in our results was the fact that the more the EL increased, the more the participant preferred to stay away from SC patients or remain indifferent to them. While persons with a low EL thought that they must support these patients even though it could be contagious, this could be explained by the importance of the family and the religious links in our population, particularly in those with a low and moderate SEL who share a common home and a lifestyle.

From another perspective, $69.7 \%$ of our participants, especially younger patients with moderate or high SEL and EL had already heard of this type of cancer from different sources, such as SC patients, dermatologists and particularly the media (TV, internet..). This media tools may be an interesting way of sensitization that we can use as a strategy of SC prevention. According to our results, each category of the population may be educated using different media tools; for young educated persons the internet and the social media are the most effective way of giving information, while TV remains the best way of sensitization for illiterates and aged persons.

Regarding the way of announcing the diagnosis of cancer to the patient, Our results confirmed that it must vary according to the gender. This fact must be taken into account by the health care professionals in Morocco in order to decrease the disease burden, especially in women, but in the same time, we should be careful, because, it may lead the patient to neglect his disease if he did not know the gravity of it. 
Based on these results, we deduced that it's crucial to seek ways to correct the false ideas and the common errors regarding this special type of cancer in an attempt to prevent and to establish a SC surveillance and to facilitate its early detection.

Unfortunately, Guidelines regarding the SC screening are inconsistent and depend on the economic level of countries and natural factors (sunshine, climate, altitude), phototype and customs. However, several prominent national organizations recommended and emphasized sun-protective behaviors [27], education of health professionals, including nurses, in addition to improving strategies of SC and melanoma screening [28-32].

Ultimately, Despite all the barriers to SC prevention in Morocco, like financial issues, the lack of national guidelines, awareness, and availability of physicians. This overall burden must lead the health system in Morocco to consider this serious health problem and to try to establish a general approach to deal with it, using different ways of communication like the internet [33]; the TV and the programs of teaching health maintenance, the school programs for children; the sun protection guidelines and the SC screening programs not only for dermatologists, but for all the health care professionals.

This study is not without limitations, especially concerning our choice of participants; all the sections of the population were represented in the study sample, but the percentage of these sections was not equal. Although participants were chosen randomly and we tried to have a representative sample of all categories of the population, $78.3 \%$ of our participants were young (between 18 and 45 years old) and having an academic degree in $51 \%$ of cases.

\section{Conclusion}

Due to the lack of knowledge or the underestimation of SCs in our population, as we proved it in our study, efforts are needed to promote SC's surveillance and screening in Morocco, in addition to the establishment of effective campaigns of SC sensitization.

\section{Abbreviations}

BCC: Basal cell carcinoma; EL: Educational level; NMSC: Non-melanoma skin cancers; SC: Skin cancer; SCC: Squamous cell carcinoma; SEL: Socio economic level

\section{Acknowledgements}

We are indebted to all patients who participated in this study and gave their consent. We thank all volunteer investigators and the medical staff of the department of Dermatology and clinical epidemiology for their enormous help. Special thanks to the psychiatrist «Dr.M Jaafari » for his help in the questionnaire elaboration.

\section{Funding}

The authors declare that they have no fundings.

\section{Availability of data materials}

Please contact author for data requests.

\section{Authors' contributions}

Conception and design: KA, AM. Acquisition, analysis and interpretation of data: KA, BH, GS. Drafting the article: KA; BH. Revising it critically for important intellectual content: KA, ES, MFZ. All authors read and approved the final manuscript.

\section{Competing interests}

The authors declare that they have no competing interests.

\section{Ethics approval and consent to participate}

Ethics approval was obtained from the ethics committees in the University Hospital Center Hassan II in Fez-Morocco; all the patients were informed of the conditions related to the study and gave their informed consent for the study and for publication.

\section{Author details}

'Department of dermatology, University Hospital Hassan II, 202 Hay Mohamadi, Fez, Morocco. ${ }^{2}$ Department of clinical epidemiology and scientific research, University Hospital Hassan II, Fez, Morocco.

Received: 1 January 2017 Accepted: 15 February 2017

Published online: 17 February 2017

\section{References}

1. Cakir BO, Adamson P, Cingi C. Epidemiology and Economic Burden of Nonmelanoma Skin Cancer. Facial Plastic Clinics of North America. 2012; 20(4):419-22.

2. Benchikhi H, Naciri-Bennani B, Tarwate M, Hali F, Khadir K, Zouhair K, et al. Évolution de la répartition des cancers cutanés vus dans le service de dermatologie de Casablanca entre les périodes 1971-1991 et 1992-2011. Ann Dermatol Vénéréol. 2012;139(12):838-9.

3. Lakjiri S, Inani K, Gallouj S, Meziane M, Mikou W, Mernissi FZ. Les mélanomes : expérience de CHU Hassan II, Fès. Ann Dermatol Vénéréol. 2013; 140(Supplement 1):S106.

4. Roebuck H, Moran K, MacDonald DA. PhD, Shumer S, McCune R L. Assessing skin cancer prevention and detection educational needs : an andragogical approach. J Nurs Pract. 2015;11(4):409-16.

5. Kyle J, Hammitt J, Lim H, et al. Economic evaluation of the U.S. Environmental Protection Agency's SunWise program: sun protection education for young children. Am Acad Pediatr. 2008;121:1074-84.

6. de Boz J, Fernández-Morano T, Padilla-Espana L, Aguilar-Bernier M, RivasRuiz F, de Troya-Martín M. Skin Cancer Prevention and DetectionCampaignat Golf Courses on Spain's Costa del Sol. Actas Dermosifiliogr. 2015;106:51-60.

7. Housman TM, Feldman SR, Williford PM, Feischer AB, Goldman ND, Acostamiedo JM, et al. Skin cancer is among the most costly of all cancers to treat for the Medicare population. J Am Acad Dermatol. 2003:48:425-9.

8. Housman TM, Feldman SR, Williford PM, Feischer AB, Goldman ND, Acostamiedo JM, et al. Skin cancer is among the most costly of all cancers to treat for the Medicare population. J Am AcadDermatol. 2003;48:425-9.8Montague M, Borland R, Sinclair C. Slip! Slop! Slap! andSunsmart, 1980-2000: Skin Cancer Control and 20 Years of Population-Based Campaigning. Health Educ Behav. 2001;28:290-305.

9. Aceituno-Madera P, Buendía-Eisman A, Arias-Santiago S, Serrano-Ortega S. Evolución de la incidencia del cáncer de piel en el periodo 1978-2002. Actas Dermosifiliogr. 2010;101:39-46.

10. Van der Leest RJ, de Vries E, Bulliard JL, Paoli J, Peris K, Stratigos AJ, et al. The Euromelanoma skin cancer prevention campaign in Europe: Characteristics and results of2009 and 2010. J Eur Acad Dermatol Venereol. 2011;25:1455-65.

11. Geller AC, Greinert R, Sinclair C, Weinstock MA, Aitken J, Boniol M, et al. A nationwide population-based skin cancer screening in Germany: Proceedings of the first meeting of the International Task Force on Skin Cancer Screening and Prevention (September 24 and 25, 2009). Cancer Epidemiol. 2010;34:355-8.

12. Mc Carthy WH. The Australian experience in sun protection and screening for melanoma. J Surg Oncol. 2004;86:236-45.

13. Anton WR, Janda M, Baade PD, Anderson P. Primary prevention of skin cancer: A review of sun protection in Australia and internationally. Health Promot Int. 2004;19:369-78. 
14. Diepgen TL, Mahler $\mathrm{V}$. The epidemiology of skin cancer. $\mathrm{Br} J$ Dermatol. 2002;146(Suppl61):1-6.

15. Gandhi SA, Kampp J. Skin Cancer Epidemiology, Detection, and Management. Med Clin North Am. 2015;99(6):1323-35.

16. Bickers DR, Lim HW, Margolis D, et al. The burden of skin diseases: 2004 a jointproject of the American Academy of Dermatology Association and the Society forlnvestigative Dermatology. J Am Acad Dermatol. 2006;55(3):490-500.

17. Alberg AJ, Herbst RM, Genkinger JM, Duszynski KR. Knowledge,attitudes, and behaviors towards skin cancer Maryland youths. J Adolesc Health. 2002; 31(4):372-7.

18. Kaminska-Winciorek G, Wydmanski J, Gajda M, Tukiendorf A. Melanoma awareness and prevalence of dermoscopic examination among internet users: a cross-sectional survey. Postepy Dermatol Alergol. 2016;33(6):421-8.

19. Korta DZ, Saggar V, Wu TP, Sanchez M. Racial differences in skin cancer awareness and surveillance practices at a public hospital dermatology clinic. JAAD. 2014;70(2):312-7.

20. Gordon R. Skin cancer: an overview of epidemiology and risk factors. Semin Oncol Nurs. 2013;29(3):160-9.

21. Harth Y, Schemer A, Friedman-Birnbaum R. Awarness to photodamage versus the actual use of sun protection methods by young adults. J Eur Acad Dermatol Venereol. 1995;4(3):260-6.

22. Cooley JH, Quale LM. Skin cancer preventive behavior and sun protection recommendations. Semin Oncol Nurs. 2013;29(3):223-6.

23. Agbai ON, Buster K, Sanchez M, et al. Skin cancer and photoprotection in people of color: a review and recommendations for physicians and the public. JAAD. 2014;70(4):748-62.

24. Miller KA, Huh J, Unger JB, Richardson JL, Allen MW, Peng DH, Cockburn MG. Patterns of sun protective behaviors among Hispanic children ina skin cancer prevention intrvention. Prev Med. 2015;81:303-8.

25. Natalie Schuz, MichaelEid. Sun Exposure and Skin Cancer Prevention. International Encyclopedia of the Social \& Behavioral Sciences, 2nd edition, Volume 23: 696-700.

26. E Senel, I Süslü.Knowledge, attitudes, and behaviors regarding sun protection, effects of the sun, and skin cancer among Turkish high school students and teachers. Dermatol Sin. 2015;33(4):187-90.

27. SunWise. The U.S. EPA's SunWise program: a roadmap. 2014. http://www2.epa. gov/sunwise/us-epas-sunwise-program-roadmap/. Accessed 16 May 2014.

28. McGuire S, Secrest A, Andrulonis R, Ferris L. Surveillance of patients for early detection of melanoma: patterns in dermatologist vs. patient discovery. Arch Dermatol. 2011;258(6):673-8.

29. Siegel V. Exploring the role of the nurse in skin cancer prevention. Dermatol Nurs. 2010;4(12):18-22.

30. Coups EJ, Stapleton JL, Hudson SV, Medina-Forrester A, Rosenberg SA, Gordon M, Natale-Pereira A, Goydos JS. Skin cancer surveillance behaviors among US Hispanic adults. JAAD. 2013;68(4):576-84.

31. Emmons KM, Geller AC, Puleo E, Savadatti SS, Hu SW, Gorham S, Werchniak AE. Dana-Farber skin cancer screening Group. Skin cancer education and early detection at the beach: a randomized trial of dermatologist examination and biometric feedback. JAAD. 2011;64(2):282-9.

32. Christos PJ, Oliveria SA, Masse LC, McCormick LK, Halpern AC. Skin cancer prevention and detection by nurses: attitudes, perceptions, and barriers. J Cancer Educ. 2004;19(1):50-7.

33. Heckman C, Darlow S, Munshi T, Caruso C, Ritterband L, Raivitch S, Fleisher L, Manne S. Development of an Internet Intervention to Address Behaviors Associated with Skin Cancer Risk among Young Adults. Internet Interv. 2015; 2(3):340-50.

\section{Submit your next manuscript to BioMed Central and we will help you at every step:}

- We accept pre-submission inquiries

- Our selector tool helps you to find the most relevant journal

- We provide round the clock customer support

- Convenient online submission

- Thorough peer review

- Inclusion in PubMed and all major indexing services

- Maximum visibility for your research

Submit your manuscript at www.biomedcentral.com/submit

) Biomed Central 